\title{
Papers
}

\section{Suicide within 12 months of contact with mental health services: national clinical survey}

\author{
Louis Appleby, Jenny Shaw, Tim Amos, Ros McDonnell, Catherine Harris, Kerry McCann, \\ Katy Kiernan, Sue Davies, Harriet Bickley, Rebecca Parsons
}

\begin{abstract}
Objective To describe the clinical circumstances in which psychiatric patients commit suicide.

Design National clinical survey.

Setting England and Wales.

Subjects A two year sample of people who had committed suicide, in particular those who had been in contact with mental health services in the 12 months before death.
\end{abstract}

Main outcome measures Proportion of suicides in people who had had recent contact with mental health services; proportion of suicides in inpatients; proportion of people committing suicide and timing of suicide within three months of hospital discharge; proportion receiving high priority under the care programme approach; proportion who were recently non-compliant and not attending.

Results 10040 suicides were notified to the study between April 1996 and March 1998, of whom 2370 (24\%; 95\% confidence interval 23\% to $24 \%$ ) had had contact with mental health services in the year before death. Data were obtained on 2177 , a response rate of $92 \%$. In general these subjects had broad social and clinical needs. Alcohol and drug misuse were common. $358(16 \%$; $15 \%$ to $18 \%)$ were psychiatric inpatients at the time of death, $21 \%(17 \%$ to $25 \%)$ of whom were under special observation. Difficulties in observing patients because of ward design and nursing shortages were both reported in around a quarter of inpatient suicides. 519 (24\%; $22 \%$ to $26 \%)$ suicides occurred within three months of hospital discharge, the highest number occurring in the first week after discharge. 914 (43\%; $40 \%$ to $44 \%)$ were in the highest priority category for community care. 488 (26\% excluding people whose compliance was unknown; $24 \%$ to $28 \%$ ) were non-compliant with drug treatment while $486(28 \% ; 26 \%$ to $30 \%)$ community patients had lost contact with services. Most people who committed suicide were thought to have been at no or low immediate risk at the final service contact. Mental health teams believed suicide could have been prevented in 423 (22\%; $20 \%$ to $24 \%)$ cases.

Conclusions Several suicide prevention measures in mental health services are implied by these findings, including measures to improve compliance and prevent loss of contact with services. Inpatient facilities should remove structural difficulties in observing patients and fixtures that can be used in hanging. Prevention of suicide after discharge may require earlier follow up in the community. Better suicide prevention in psychiatric patients is likely to need measures to improve the safety of mental health services as a whole, rather than specific measures for people known to be at high risk.

\section{Introduction}

The risk of suicide is high in most mental disorders, estimates of risk generally suggesting a fivefold to 15-fold increase. ${ }^{1}$ High suicide rates are particularly associated with acute episodes of illness, ${ }^{2}$ recent hospital discharge, ${ }^{34}$ social factors such as living alone, ${ }^{5}$ and features of clinical history such as substance misuse and non-fatal self harm. ${ }^{7}$ However, comparatively little is known about the clinical care being provided to psychiatric patients before suicide.

The national confidential inquiry into suicide and homicide by people with mental illness was established in 1992 and has been based at the University of Manchester since 1996. Its aims are to collect detailed clinical data on people who commit suicide or homicide and who have been in contact with mental health services and to recommend changes to clinical practice and policy that will reduce the risk of suicide and homicide by psychiatric patients. The inquiry is planned to run until 2001, but an analysis of its data on a two year sample of suicides was agreed at the time of its move to Manchester. The specific objectives during this period of data collection were:

- To estimate the proportion of people who commit suicide in the general population who have been in contact with mental health services in the previous 12 months, and to describe their main characteristics

- To estimate the number of suicides in psychiatric inpatients and to describe their suicide methods and circumstances of care, including degree of nursing observation

- To estimate the number of suicides in patients discharged from inpatient care in the previous three months, to record their timing in relation to discharge, and to test the hypotheses that, in comparison with other people who commit suicide under psychiatric

\author{
Editorial by Geddes \\ National \\ Confidential \\ Inquiry into Suicide \\ and Homicide by \\ People with Mental \\ Illness, School of \\ Psychiatry and \\ Behavioural \\ Sciences, University \\ of Manchester, \\ Withington \\ Hospital, \\ Manchester \\ M20 8LR \\ Louis Appleby, \\ director \\ Jenny Shaw, \\ assistant director \\ Tim Amos, \\ clinical research fellow \\ Ros McDonnell, \\ project manager \\ Catherine Harris, \\ research worker \\ Kerry McCann, \\ research worker \\ Katy Kiernan, \\ research assistant \\ Sue Davies, \\ research associate \\ Harriet Bickley, \\ research worker \\ Rebecca Parsons, \\ research worker \\ Correspondence to: \\ Professor Appleby \\ Louis.Appleby@ \\ man.ac.uk
}

BMJ 1999;318:1235-9 
care in the community, they have higher rates of recent readmission and self discharge and shorter final admissions $^{4}$

- To estimate the proportion of suicides who were given highest priority under the care programme approach, in which patients with mental illness are allocated to different degrees of care according to their needs, those with highest priority receiving regular multidisciplinary review ${ }^{8}$

- To estimate the frequency of key problems in service provision-namely, non-compliance with treatment, failure to attend, and loss of contact-in the sample

- To examine the final contact between patient and mental health services, particularly the timing of contact in relation to suicide and the estimate of risk made by services

- To obtain the views of mental health teams on how each suicide might have been prevented.

A brief report on the first six months of data collection has been published. ${ }^{9}$ This current paper is the basis of a report to be published by the Department of Health. ${ }^{10}$ Findings on homicide are published in the accompanying paper. ${ }^{11}$

\section{Subjects and methods}

The three stages of data collection were the collection of a comprehensive national sample, irrespective of mental health history; the identification of people within the sample who had been in contact with mental health services in the 12 months before death; and the collection of clinical data about these people.

\section{Comprehensive national sample}

Information on deaths with a verdict of suicide or an open verdict in a coroner's court was forwarded regularly to the inquiry by the directors of public health in the 105 health authority districts in England and Wales. Open verdicts are often reached in cases of likely suicide, and some or all open verdict conventionally included in research on suicide. ${ }^{12}{ }^{13}$ In this study open verdicts were included unless it was clear that suicide was not considered at inquest-for example, in the cases of children and deaths from unexplained medical causes. These suicides and probable suicides are referred to as suicides in this paper. The sample presented here consists of suicides recorded by directors of public health in the 24 months from 1 April 1996, supplemented with cases recorded as suicide or deaths from undetermined external cause (equivalent to open verdicts) obtained from the Office for National Statistics for the same period.

\section{Identification of mental health service contact}

Identifying details on each suicide were submitted to the main hospitals providing mental health services to residents of the dead person's health district. When hospital records showed that contact had occurred in the 12 months before suicide the person became an inquiry case and the responsible psychiatrist was identified from hospital records. All 188 local mental health services in England and Wales regularly returned data to the inquiry. We arranged for cases to be directly reported from units that have multidistrict catchment areas, including regional forensic psychiatry units, or that have no catchment area, including national units and private hospitals.

We assessed the accuracy of detecting a previous contact with a hospital after 12 months of collecting data on a nine month sample of 355 suicides from 16 hospitals in north west England. Overall, 63 of the 65 $(97 \%)$ eligible cases were detected, missed cases occurring because of misspellings of names in hospital records or in personal information notified to the inquiry. As a result a checking protocol was developed and recommended to hospitals.

\section{Collection of clinical data}

For each case the psychiatrist was sent a questionnaire and asked to complete it after discussion with other members of the mental health team. The questionnaire consisted of sections covering demographic details, clinical history, details of suicide, details of care in people who had been inpatients, details of care in people who had been in the community, final contact with services, events leading to suicide, respondents' views on prevention, and additional (qualitative) information.

\section{Statistical analysis}

The main estimates such as rate of contact with mental health services are presented as proportions with $95 \%$ confidence intervals. Descriptive social and clinical data for inquiry cases are also presented as proportions and 95\% confidence intervals. If an item of information was not available or not known for a particular case, the case was removed from the analysis of that item; the denominator in all estimates is therefore the number of valid cases, and any changes in the size of the denominator are the result of this. Similarly, tables 1 and 3 and the figure exclude cases for which information was not known. $\chi^{2}$ tests were used to compare groups within the total sample, with significance set at $\mathrm{P}=0.01$.

\section{Results}

We received notifications of 10040 suicides -6682 cases in which the inquest verdict was suicide and 3358 in which it was an open verdict or death from undeter-

Table 1 Cause of death in people who committed suicide within 12 months of contact with mental health services. Values are numbers of people

\begin{tabular}{lcc} 
Cause of death & Men $(\mathbf{n}=\mathbf{1 3 6 9})$ & Women $(\mathbf{n}=\mathbf{7 1 2})$ \\
\hline Hanging & 500 & 154 \\
\hline Self poisoning: & 123 & 119 \\
\hline Psychotropic drugs & 33 & 39 \\
\hline Paracetamol & 25 & 13 \\
\hline Opiate & 14 & 34 \\
\hline Other analgesic & 154 & 116 \\
\hline Other or unknown & 140 & 27 \\
\hline Carbon monoxide poisoning & 186 & 89 \\
\hline Jumping or multiple injuries & 77 & 43 \\
\hline Drowning & 11 & 3 \\
\hline Firearms & 26 & 7 \\
\hline Cutting or stabbing & 25 & 31 \\
\hline Suffocation & 20 & 16 \\
\hline Burning & 7 & 0 \\
\hline Electrocution & 28 & 21 \\
\hline Other specified & &
\end{tabular}


Table 2 Social and clinical characteristics of people who committed suicide within 12 months of contact with mental health services. Values are numbers (percentages; $95 \%$ confidence intervals) unless stated otherwise

\section{No}

\begin{tabular}{|c|c|}
\hline & $\begin{array}{c}\text { No } \\
\text { (\%; } 95 \% \text { Cl) }\end{array}$ \\
\hline \multicolumn{2}{|l|}{ Social and demographic variables } \\
\hline Median age (range) (years) $(n=2177)$ & $41(15-95)$ \\
\hline Male sex $(n=2177)$ & $1434(66 ; 64$ to 68$)$ \\
\hline \multicolumn{2}{|l|}{ Ethnic origin $(n=2152)$ : } \\
\hline White & $2040(95 ; 94$ to 96$)$ \\
\hline Indian subcontinent & $43(2 ; 1$ to 3$)$ \\
\hline Black & $39(2 ; 1$ to 2$)$ \\
\hline Other & $30(1 ; 1$ to 2$)$ \\
\hline \multicolumn{2}{|l|}{ Marital status $(n=2144)$ : } \\
\hline Single & $827(39 ; 37$ to 41$)$ \\
\hline Married or cohabiting & $603(28 ; 26$ to 30$)$ \\
\hline Divorced or separated & $549(26 ; 24$ to 27$)$ \\
\hline Widowed & $165(8 ; 7$ to 9$)$ \\
\hline \multicolumn{2}{|l|}{ Employment status $(n=2115)$ : } \\
\hline Employed & $362(17 ; 16$ to 19$)$ \\
\hline Unemployed & $817(39 ; 37$ to 41$)$ \\
\hline Long term sick & $407(19 ; 18$ to 21$)$ \\
\hline Housewife or husband & $171(8 ; 7$ to 9$)$ \\
\hline Retired & $138(7 ; 5$ to 8$)$ \\
\hline Full time student & $36(2 ; 1$ to 2$)$ \\
\hline Other & $184(9 ; 7$ to 10$)$ \\
\hline \multicolumn{2}{|l|}{ Accommodation $(n=2121)$ : } \\
\hline House or flat & 1821 (86; 84 to 87$)$ \\
\hline Hostel & $94(4 ; 4$ to 5$)$ \\
\hline Homeless & $53(3 ; 2$ to 3$)$ \\
\hline Bed and breakfast & $22(1 ; 1$ to 1$)$ \\
\hline Prison & $16(1 ; 0$ to 1$)$ \\
\hline Other & $115(5 ; 4$ to 6$)$ \\
\hline \multicolumn{2}{|l|}{ Living circumstances ( $\mathrm{n}=2116)$ : } \\
\hline Alone & $873(41 ; 39$ to 43$)$ \\
\hline With spouse or partner & $611(29 ; 27$ to 31$)$ \\
\hline With parent(s) & $284(13 ; 12$ to 15$)$ \\
\hline With children only & $89(4 ; 3$ to 5$)$ \\
\hline Other shared & 95 (4; 4 to 5$)$ \\
\hline Other & 164 (8; 7 to 9$)$ \\
\hline
\end{tabular}

\section{Clinical variables}

Primary diagnosis $(\mathrm{n}=2145)$ :

\begin{tabular}{lc}
\hline Schizophrenia and other delusional disorder & $443(21 ; 19$ to 22$)$ \\
\hline Affective disorder (bipolar and depression) & $891(42 ; 39$ to 44$)$ \\
\hline Neurotic disorder & $74(3 ; 3$ to 4$)$ \\
\hline Alcohol dependence & $200(9 ; 8$ to 11$)$ \\
\hline Drug dependence & $92(4 ; 3$ to 5$)$ \\
\hline Personality disorder & $228(11 ; 9$ to 12$)$ \\
\hline Other & $217(10 ; 9$ to 11$)$ \\
\hline Any secondary diagnosis $(\mathrm{n}=2151):$ & \\
\hline Affective disorder (bipolar and depression) & $361(17 ; 15$ to 18$)$ \\
\hline Neurotic disorder & $217(10 ; 9$ to 11$)$ \\
\hline Alcohol dependence & $203(9 ; 8$ to 11$)$ \\
\hline Drug dependence & $179(8 ; 7$ to 10$)$ \\
\hline Personality disorder & $276(13 ; 11$ to 14$)$ \\
\hline Other & $145(7 ; 6$ to 8$)$ \\
\hline Duration of history $(\mathrm{n}=2129):$ & $466(22 ; 20$ to 23$)$ \\
\hline$<12$ months & $636(30 ; 28$ to 32$)$ \\
\hline $1-5$ years & $1027(48 ; 46$ to 50$)$ \\
\hline$>5$ years & \\
\hline Previous admissions $(\mathrm{n}=2148):$ & $700(33 ; 31$ to 35$)$ \\
\hline None & $1126(52 ; 50$ to 55$)$ \\
\hline $1-5$ & $322(15 ; 13$ to 17$)$ \\
\hline$>5$ & $1347(63 ; 60$ to 65$)$ \\
\hline History of self harm $(\mathrm{n}=2155)$ & $397(19 ; 17$ to 20$)$ \\
\hline History of violence $(\mathrm{n}=2133)$ & $488(26 ; 36$ to 40$)$ \\
\hline History of alcohol misuse $(\mathrm{n}=2145)$ & \\
\hline History of drug misuse $(\mathrm{n}=2142)$ & to 28$)$ \\
\hline Non-compliance in month before suicide $(\mathrm{n}=1863)$ & \\
\hline &
\end{tabular}

mined external cause. Of these, 2370 (24\%; $95 \%$ confidence interval $23 \%$ to $24 \%$ ) were confirmed to have been in contact with mental health services in the year before death. This figure varied widely between districts, from $14 \%$ to $36 \%$. Completed questionnaires were received on 2177 cases, a response rate of 92\%; the findings below refer to these cases.

Means of suicide-Table 1 shows the method of suicide. The commonest methods were hanging (men) and self poisoning by overdose (women). The commonest category of drug used in overdose was psychotropic drugs. Violent or active methods such as hanging and jumping from a height were used in 1244 $(57 \% ; 55 \%$ to $59 \%)$, while in the total population sample such methods were used in 5405 (54\%; 53\% to $55 \%)$.

Social and clinical characteristics-Table 2 shows social and clinical characteristics. The ratio of men to women was 1.93:1, lower than the ratio of 2.97:1 in the general population. Substantial rates of social difficulties and clinical problems were evident. Overall, $41 \%$ (39\% to $43 \%)$ lived alone and $3 \%(2 \%$ to $3 \%)$ were homeless. The commonest primary diagnoses were depression, schizophrenia, personality disorder, and alcohol dependence. Around half also had a secondary diagnosis. Alcohol and drug misuse were common: $17 \%(16 \%$ to $19 \%)$ were misusing both alcohol and drugs. In all, 466 suicides (22\%; 20\% to 23\%) occurred in the first year after the onset of the primary disorder.

Inpatient suicides - A total of 358 suicides (16\%; 15\% to $18 \%)$ were psychiatric inpatients. Of these, $82(23 \%$; $19 \%$ to $27 \%$ ) occurred in the first week after admission and $144(40 \% ; 35 \%$ to $45 \%)$ when discharge was being planned. One hundred and twenty $(34 \% ; 29 \%$ to $38 \%)$ occurred on the ward itself, $47(13 \% ; 10 \%$ to $17 \%)$ in or around hospital premises, and 191 (53\%; 48\% to 58\%) away from the hospital. In all, 134 of the $238(56 \% ; 50 \%$ to $62 \%$ ) patients who committed suicide off the ward had left with staff agreement. Hanging was the commonest method, accounting for 142 (40\%; 35\% to $45 \%)$ inpatient suicides, including $81(68 \% ; 60 \%$ to $76 \%$ ) of those occurring on the ward. Seventy six patients $(21 \% ; 17 \%$ to $26 \%)$ were under special observation, $11(3 \% ; 1 \%$ to $5 \%)$ constantly and $65(18 \% ; 14 \%$ to $22 \%)$ every 5 -30 minutes. In 84 cases ( $24 \%$; $20 \%$ to $28 \%$ ) there were difficulties in observing patients because of ward design. In 82 cases (25\%; $20 \%$ to $29 \%)$ the wards had a shortage of nurses.

Suicide after discharge - A total of 519 (24\%; 22\% to $26 \%$ ) suicides occurred within three months of discharge from inpatient care. They peaked in the first week after leaving hospital (figure), the highest number occurring on the day after discharge. In all, 186 (41\%; $37 \%$ to $45 \%$ ) occurred before the first follow up appointment. Compared with all other suicides among patients in the community who had previously been admitted, these suicides were associated with final admissions lasting fewer than seven days (29\% $v 19 \%$; $\left.\chi_{1}^{2}=16.97 ; \quad \mathrm{P}<0.001\right)$, readmission within three months of the previous admission (23\% v $13 \%$; $\chi_{1}^{2}=21.9 ; \mathrm{P}<0.001$ ), and discharge against medical advice, at patient's request, or after breach of ward rules by the patient $\left(32 \% \vee 18 \% ; \chi_{1}{ }_{1}=29.89 ; \mathrm{P}<0.001\right)$. Removing those who discharged themselves from the analysis did not affect the pattern of timing in the figure. 


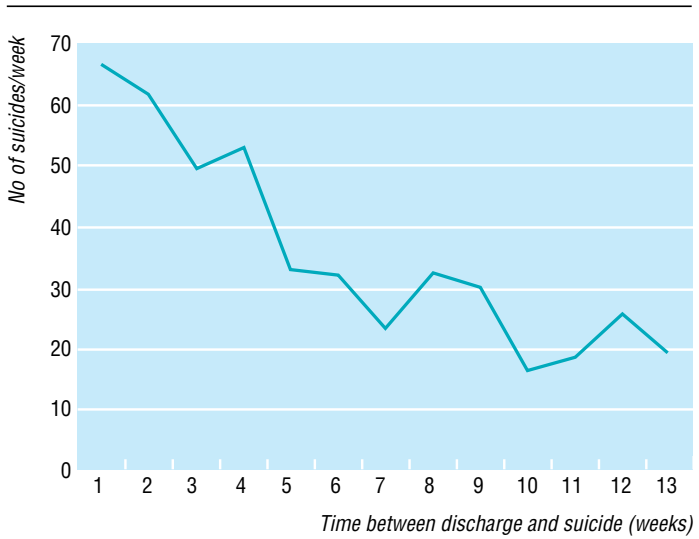

Numbers of suicides each week after discharge

Suicide and the care programme-Nine hundred and fourteen $(42 \% ; 40 \%$ to $44 \%)$ people who committed suicide had been given highest priority under the care programme approach, including $318(72 \% ; 68 \%$ to $76 \%$ ) of those with a diagnosis of schizophrenia.

Non-compliance and loss of contact-In the inquiry case sample 488 people ( $26 \%$ of those for whom compliance was known; $24 \%$ to $28 \%$ ) had been noncompliant with drug treatment in the month before death. Of the community patients, $546(34 \% ; 33 \%$ to $35 \%$ ) had been non-compliant in the previous three months, mainly because of lack of insight (196, 39\%; $34 \%$ to $43 \%$ ) and drug side effects (59, $12 \%$; $9 \%$ to $14 \%)$. A total of $486(28 \% ; 26 \%$ to $30 \%)$ people in the community were said by respondents to have lost contact with services. The response of services was known in 404 cases; no further action was taken in 190 (47\%; $42 \%$ to $52 \%)$.

Final contact with services-A total of 1069 people who committed suicide (50\%; $48 \%$ to $52 \%$ ) had been in contact with mental health services in the week before death, $422(20 \%$; $18 \%$ to $21 \%)$ in the previous 24 hours (table 3). A large proportion of those who had been in contact in the previous 24 hours were inpatients, but the general pattern of close contact remained when inpatient suicides were removed from the analysis (table 3). At final contact the immediate risk of suicide was estimated as absent in $627(30 \%$; $28 \%$ to $32 \%)$, low in $1132(54 \%$; 52\% to $57 \%)$, moderate in $273(13 \%$; $12 \%$ to $15 \%)$, and high in $46(2 \% ; 2 \%$ to $3 \%)$.

Prevention-Mental health teams regarded 423 $(22 \% ; 20 \%$ to $24 \%)$ suicides as preventable, but in 1337 $(61 \% ; 59 \%$ to $63 \%)$ they were able to specify at least one measure that would have reduced risk. Most often this was improved patient compliance (632 cases, 29\%; $27 \%$ to $31 \%$ ) or closer supervision ( 558 cases, $26 \%$; $24 \%$ to $27 \%$ ).

Table 3 Timing of last contact with mental health services in people who committed suicide within 12 months of contact. Values are numbers of people

\begin{tabular}{lcc} 
& $\begin{array}{c}\text { Community patients } \\
(\mathbf{n}=\mathbf{1 7 8 1})\end{array}$ & Inpatients $(\mathbf{n = 3 5 6 )}$ \\
\hline Time between last contact and suicide: & & \\
\hline$<24$ hours & 145 & 277 \\
\hline $1-7$ days & 575 & 52 \\
\hline $1-4$ weeks & 495 & 1 \\
\hline $5-13$ weeks & 246 & 1 \\
\hline$>13$ weeks & 320 &
\end{tabular}

\section{Discussion}

To our knowledge, this is the largest reported sample of suicides by psychiatric patients, and its size allows us to estimate accurately the rate of the main social and clinical characteristics. It also allows us to measure suicide rates in particular groups, such as homeless people and ethnic minority groups (table 2), or treatment settings, such as inpatient wards. It shows the aspects of mental health services that should be strengthened if suicide prevention is to be improvedfor example, early follow up after hospital discharge. However, it also shows the limits of prevention in clinical practice. Around a quarter of people who committed suicide had been in contact with mental health services in the year before death; a $15 \%$ reduction in the population suicide rate, the target in the Health of the Nation, ${ }^{14}$ is unlikely to be achieved without a broadly based strategy in which social measures and initiatives in primary care, as well as mental health services, play a part.

\section{Methodological issues}

The national confidential inquiry is a survey of clinical activity before suicide rather than a case-control study, and two important limitations of its findings arise from this. Firstly, without controls aetiological conclusions cannot be drawn. Secondly, information was provided by clinicians who may have been biased by their awareness of outcome, particularly on variables such as estimation of risk before suicide. In addition, the questionnaires were not formally tested for reliability or validity.

However, many of the questionnaire items concerned omissions or problems in care such as non-compliance with drug treatment, and these are likely to be contributory when they occur before suicide, at least in some cases. Most of the items in the questionnaire were factual rather than subjective, and there were few reported disagreements between members of mental health teams submitting data. The potential for bias because of awareness of outcome is also a problem in many other methods of suicide research, including psychological autopsy studies, ${ }^{15}$ regarded as the most informative method of investigation.

\section{Suicide prevention measures}

The findings suggest a range of measures which could improve suicide prevention by mental health services, including measures to increase compliance with treatment, prevent loss of contact with services, and reduce access to large quantities of psychotropic drugs. However, intervention studies showing the effectiveness of clinical measures in reducing suicide have not been conducted. For example, although improved compliance in psychiatric patients has been shown as a result of intensive community support (assertive outreach $)^{16}{ }^{17}$ and detailed discussion of drug treatments (compliance therapy), ${ }^{18}$ the impact of these approaches on suicidal behaviour has not been assessed.

Specific measures may be needed to reduce inpatient suicides and suicides within three months of hospital discharge. The number of inpatient suicides, around 180 per year, is around three times the number of prison suicides ${ }^{19}$ yet attracts much less public atten- 
Key messages

- Around a quarter of people who commit suicide have been in contact with mental health services in the year before death-over 1000 cases annually

- Of these cases, $16 \%$ are psychiatric inpatients and $24 \%$ have been discharged from inpatient care in the previous three months

- Problems of observation caused by ward design and nursing shortages are common in cases of inpatient suicide

- Suicide in former inpatients occurs most commonly in the week after discharge

- Non-compliance with treatment and loss of contact with services are common before suicide

tion. Most of these deaths are by hanging, indicating the need for the removal of structures that make hanging easier such as non-collapsible curtain rails. A quarter of inpatient suicides occur in wards with difficulties in observing patients; this implies that some wards are unsuitable for the care of acutely ill patients. Suicides after discharge from hospital suggest the need for early-in some cases, immediate-follow up after discharge.

Most psychiatric patients who commit suicide are not regarded as being at high immediate risk at their final contact with mental health services. Better suicide prevention may therefore need changes to services for all patients rather than specific initiatives for those known to be at highest risk. A series of recommendations is to be published by the Department of Health ${ }^{10}$; these are based on the above findings and are intended to improve the safety of mental health services as a whole.

We acknowledge the help of district directors of public health; health authority and trust contacts; consultant psychiatrists for completing the questionnaires; Professor Graham Dunn, professor of biostatistics, University of Manchester, for comments on the presentation of the statistical analysis.
Contributors: LA and JS were grant holders and led the design and coordination of the project, data collection, analysis of data, and the writing of the paper. TA and RM contributed to the design of the study and the coordination of data collection, project management, and analysis. $\mathrm{CH}, \mathrm{KM}, \mathrm{SD}, \mathrm{HB}$, and RP contributed to data collection and data management. KK contributed to data management and analysis. All authors approved the final version of the paper. LA is guarantor for the study

Funding: Department of Health; Welsh Office.

Competing interests: None declared.

1 Harris EC, Barraclough B. Suicide as an outcome for mental disorders. $\mathrm{Br}$ J Psychiatry 1997;170:205-28

2 Copas JB, Freeman-Browne DL, Robin AA. Danger periods for suicide in patients under treatment. Psychol Med 1971;1:400-4.

3 Goldacre M, Seagroatt V, Hawton K. Suicide after discharge from psychiatric in-patient care. Lancet 1993;342:283-6.

4 Geddes JR, Juszczak E. Period trends in rate of suicide in first 28 days after discharge from psychiatric hospital in Scotland, 1968-92. BMJ 1995:311:357-60

5 Roy A. Risk factors for suicide in psychiatric patients. Arch Gen Psychiatry 1982; 39:1089-95.

6 Henriksson MM, Aro HM, Marttunen MJ, Heikkinen ME, Isometsä ET. et al. Mental disorders and comorbidity in suicide. Am J Psychiatry 1993;150:935-40.

7 Myers DH, Neal CD. Suicide in psychiatric patients. Br J Psychiatry 1978;133:38-44.

8 Department of Health. The care programme approach for people with a mental illness referred to the specialist psychiatric services. London: DoH, 1990 (Circular HC(90)23/LASSL(90)1.)

9 Appleby L, Shaw J, Amos T, McDonnell R, Davies S, Harris C, et al. The national confidential inquiry into suicide and homicide by people with mental illness. Progress report 1997. London: Department of Health, 1997.

10 Appleby L, Shaw J, Amos T, McDonnell R, Kiernan K, Davies S, et al. Safer services. Report of the national confidential inquiry into suicide and homicide by services. Report of the national confidential inquiry i

people with mental illness. London: HMSO, 1999.
11 Shaw J, Appleby L, Amos T, McDonnell R, Harris C, McCann K, et al. Mental disorder and clinical care in people convicted of homicide: national clinical survey. BMJ 1999;318:1240-4.

12 O'Donnell I, Farmer R. The limitations of official suicide statistics. $\mathrm{Br} \mathrm{J}$ Psychiatry 1995;166:458-61.

13 Neeleman J, Wessely S. Changes in classification of suicide in England and Wales: time trends and associations with coroners professional background. Psychol Med 1997;27:467-72

14 Department of Health. The health of the nation. Strategy for health in England. London: HMSO, 1992.

15 Hawton K, Appleby L, Platt S, Foster T, Cooper J, Malmberg A, et al. The psychological autopsy approach to studying suicide: a review of methodological issues. J Affect Disord 1998;50:269-76.

16 Dixon L, Weiden P, Torres M, Lehman A. Assertive community treatment and medication compliance in the homeless mentally ill. Am J Psychiatry 1997;154:1302-

17 Burns BJ, Santos AB. Assertive community treatment: an update of randomized trials. Psychiatr Serv 1995;46:669-75

18 Kemp R, Hayward P, Applewhaite G, Everitt B, David A. Compliance therapy in psychotic patients: randomised controlled trial. BMJ 1996; 312:345-9.

19 Home Office. Prison statistics, England and Wales 1997. London: Stationery Office, 1998. (C4017.)

(Accepted 24 March 1999)

\section{A valuable lesson}

\section{Always check the $x$ ray film}

In the early 1980s I was a senior house officer in general medicine at Harare Central Hospital, Zimbabwe. Those were years of change in a newly independent country and I had the opportunity to work with a multinational team.

Of the two histopathologists one was a friendly young Briton with a recent MRCPath degree. The other one was also an affable, but most reticent, middle aged man from the former Yugoslavia. He sat bent over his microscope from morning till evening, chain smoking silently and rapidly going through large stacks of slides. While the reports of the Yugoslav were terse those of the Briton were painstakingly detailed and methodical. We learnt to rely on both of them.

Hepatoma is extremely common in Zimbabwe and all too soon I was also inducted into the liver biopsy technique. Ultrasound had not quite made its mark, and on this patient the indications for a liver biopsy were a progressive jaundice, abnormal liver function tests, a positive hepatitis B status, and high $\alpha$-fetoprotein levels. My registrar gave me an almost perfect demonstration and I looked enviously at the sizeable chunk of tissue that he managed to tease out with a Trucut needle. Two days later the senior registrar was taking his round and requested the report of the liver biopsy. Our ward sister promptly brought it over and we all had a look. It comprised the two words "normal spleen" and was signed by the Yugoslav.

For a few seconds the three of us stood as if thunderstruck. The senior registrar was the first to regain his composure. He dashed to the $x$ ray trolley, whipped out the patient's chest $x$ ray film, and put it up for viewing. Yes, the patient had situs inversus.

Till now this was our best kept secret. But since then I have never failed to look at a patient's chest $x$ ray film before performing a procedure.

Rashid N Siddiqui, consultant chest physician, Saudi Arabia 